\author{
$\mathrm{Su}$ Tian \\ Institut za svetsku ekonomiju i politiku \\ Kineska akademija društvenih nauka
}

\title{
Pristupanje Srbije EU i prisustvo Kine na Balkanu*
}

\begin{abstract}
Sažetak
Kao prepreka na putu ka Evropskoj uniji i kopneni most Euroazije, Zapadni Balkan je dugo u fokusu međunarodne igre moći. Među zemljama Zapadnog Balkana Hrvatska se uspešno pridružuje Evropskoj uniji u 2013. godini, a ostale zemlje takođe tretiraju ulazak u EU kao jedan od glavnih prioriteta nacionalne strategije. Centripetalna sila regionalnih zemalja čini EU glavnim akterom u regionu. Inicijativom $(17+1)$ saradnje između Kine i zemalja Srednje i Istočne Evrope i inicijativom Pojas i put (BRI) u regionu, posebno u Srbiji, kineske kompanije, koje zastupaju China Road and Bridge Engineering Co. Ltd., Fabrika gvožđa i čelika Hebei i druge postižu važan komercijalni napredak na lokalnom tržištu. Trenutna pragmatična saradnja Kine i Srbije pojačava emocionalne veze dva naroda i slika privlačnu sliku odnosa između naroda i vlada, takođe, uticaj Kine u ovom regionu raste u skladu sa tim. Međutim, susret Kine i EU u Srbiji vodi do raznih spekulacija o mogućnosti konkurencije ili saradnje između Kine i EU u regionu. Neke zemlje EU, koje predstavlja Nemačka, otvoreno dovode u pitanje motive Kine za uspostavljanje inicijative Pojas i put (PiP) u Srbiji i drugim balkanskim zemljama i podstiču snažnu budnost za učešće Kine u regionu. Stoga ovaj rad ima za cilj da otkrije kako prisustvo Kine na Balkanu može da olakša pristupanje Srbije EU i da se pravilno odgovori na izazove EU u vezi sa tim pitanjima.
\end{abstract}

Ključne reči:

Inicijativa 17+1, inicijativa Pojas i put, Srbija, EU, saradnja, pristupanje Srbije EU

Analiza iznesena u ovom radu bazirana je na autorovim intervjuima ljudi angažovanih na pomenutim projektima. 


\section{ISTORIJSKI PREGLED DOGAĐANJA U REGIONU}

Krajem osamdesetih godina prošlog veka Jugoslavija se definitivno raspala zbog ekonomskog usporavanja i intenziviranja inflacije i etničkih sukoba. Nakon regionalnih previranja devedesetih godina, Slovenija i Hrvatska postale su regionalni lideri u procesu pridruživanja EU kroz pregovore o pristupanju radi postizanja bržeg ekonomskog oporavka i društvenog razvoja. Preostale bivše države članice Jugoslavije i Albanija, kao i kosovski region, koji je jednostrano proglasio nezavisnost 2008. godine, formirali su sadašnji Zapadni Balkan. Kao novi izraz koji je skovala Evropska unija, Zapadni Balkan ne samo da nosi geografske konotacije regiona, već podrazumeva i određene razlike između sebe i zemalja EU u političkom, ekonomskom, pravnom i društvenom domenu. ${ }^{1}$

U poređenju sa vremenima Jugoslavije, nivo ekonomskog i socijalnog razvoja Zapadnog Balkana još uvek je daleko ispod tadašnjeg. Jedan od zajedničkih zahteva regionalnih zemalja je da postanu široko prihvaćene evropske članice. Međutim, zbog regionalnih previranja devedesetih godina i globalne finansijske krize u 2008. godini, ekonomski oporavak regiona je već duže vreme relativno spor. Glavna, identifikovana ograničenja ekonomskog rasta u regionu su jednolična tržišna struktura, nedostatak kapitala i tehnološka nerazvijenosti ona od početka ometaju nacionalni razvoj. Stoga traženje finansijske i tehničke podrške sa spoljnih tržišta postaje jedan od glavnih zadataka Zapadnog Balkana u cilju oživljavanja svoje ekonomije. To ne samo da pruža mogućnost da se EU proširi na Istok, već pruža i mogućnost da se druge spoljne sile, uključujući Kinu, bave regionalnim poslovima Zapadnog Balkana. U ovim okolnostima, kako različite interesne grupe prilagođavaju sopstvene strategije prema Zapadnom Balkanu, pravilno upravljanje odnosima sa drugim zainteresovanim stranama postalo je ključno pitanje regionalnog razvoja i verovatno će direktno uticati na potencijalni pravac razvoja Zapadnog Balkana.

PålKolstø (2016), “'Western Balkans' as the New Balkans: Regional Names as Tools for Stigmatisation and Exclusion", Europe-Asia Studies, 68: 7, 1245-1263; Todorova, Maria (1996), Imaging the Balkans, Oxford: Oxford University Press. 


\section{PRISUSTVO KINE U SRBIJI - INICIJATIVE „17+1” I POJAS I PUT}

Stabilni kinesko-evropski odnosi preduslov su za nesmetan napredak inicijative Pojas i put u Srbiji, na Zapadnom Balkanu, pa čak i u celoj Evropi. Kina je 2012. godine potpisala „Dvanaest mera za unapređenje prijateljske saradnje sa zemljama centralne i istočne Evrope", zajedno sa 16 zemalja centralne i istočne Evrope, i po prvi put pokrenula format „16 + 1" u Poljskoj da produbi ekonomsku saradnju uglavnom u oblastima infrastrukture, telekomunikacija i održivog razvoja sa Srbijom kao jednom od najaktivnijih zemalja-učesnica. U 2019. format se prvi put proširuje jer ulazi Grčka. U okviru 17 partnera, Srbija je jedna od vodećih zemalja koja učestvuje u ovom formatu po pitanjima veličine i vrste projekata. Shodno tome, kineske kompanije postepeno ulaze na srpsko tržište. Nakon godina uspešnog poslovanja na lokalnom tržištu, ova kineska preduzeća široko su prepoznata kao pouzdan partner. A izgradnja objekata u okviru inicijative Pojas i put, u kojoj učestvuju kineska preduzeća, postepeno napreduje i razvija se u različite forme zasnovane na različitim načinima finansijske podrške. Sve u svemu, trenutni PiP građevinski projekti u Srbiji mogu da budu analizirani iz sledeće tri perspektive.

\subsection{Politički angažman}

Iz političkog aspekta, dve strane održavaju dugogodišnji prijateljski odnos još iz doba Jugoslavije. Godina 2016. obeležila je novi vrhunac bilateralnih odnosa. U junu je predsednik Si Đinping objavio svoj potpisani članak pod nazivom „Trajno prijateljstvo i istinsko partnerstvo" o svojoj državnoj poseti Srbiji ${ }^{2}$ u vodećem srpskom listu „Politika”, a Kina i Srbija su se složile da se tokom Si Đinpingove državne posete "Strateško partnerstvo", zvanično uspostavljeno 2009. godine, unapredi u "Sveobuhvatno strateško partnerstvo", koje pokazuje zajedničku posvećenost daljem produbljivanju saradnje na obostranu korist. Kao što je predsednik Si Đinping tokom državne posete Srbiji rekao: „Kina i Srbija su prijatelji i važni partneri za saradnju u svim okolnostima". ${ }^{3}$ Imajući u vidu sličnosti pitanja Tajvana i

Xi Jinping, Enduring Friendship and True Partnership, June 16, 2016; http://www.chinadaily.com.cn/world/2016xivisitee/2016-06/16/content_25737654.htm; visited on August 20, 2019.

3 Xinhua English, China, Serbia lift relations to comprehensive strategic partnership, June 19, 2016; http://english.sina.com/news/2016-06-19/doc-ifxtfmrp2327200.shtml; visited on August 20, 2019. 
Kosova, Kina i Srbija čvrsto podržavaju međusobni suverenitet i teritorijalne zahteve na međunarodnoj sceni. U međuvremenu, kinesko rukovodstvo odavno je izrazilo podršku pridruživanju Srbije EU. ${ }^{4}$ A Srbija je jedna od prvih zemalja koje su potpisale MOU o zajedničkom razvoju inicijative Pojas i put. Povoljna politička atmosfera između dve zemlje postavila je temelj za dalju saradnju u ekonomskom i socijalnom domenu.

\subsection{Ekonomska potpora}

U okvirima inicijativa „17 + 1" i PiP, praktična saradnja u ekonomskom domenu između dveju zemalja daje sve veće rezultate. U ranoj fazi bilateralne infrastrukturne saradnje, veliki broj projekata, uključujući most Mihajlo Pupin (Zemunski most), železničku prugu Beograd-Budimpešta i širenje i dogradnju elektrane Kostolac, koristili su povoljne kredite sa niskim kamatnim stopama i dugim rokovima otplate koje daju kineske državne banke, poput Izvozno-uvozne banke Kine. Poslednjih godina, reagujući na inicijative GUT (gradi-upravljaj-prenesi) i JPP (javno-privatno-partnerstvo), neki od projekata koje trenutno grade kineska preduzeća u Srbiji postepeno preusmeravaju svoje načine finansiranja sa upotrebe kineskog koncesijskog zajma na direktne investicije. Na primer, kupovina smederevske železare od strane kompanije Hebei Iron and Steel je odličan primer koji kineskim kapitalom nije samo oživeo lokalnu industriju čelika, već je strogo poštovao sve zakonske i ekološke zahteve. Avgusta 2018. godine, Shandong Linglong Tire planirao je da uloži 994.000.000 USD za izgradnju 13.620 .000 kompleta visokokvalitetnih radijalnih guma u zoni slobodne trgovine u Srbiji, što je tipičan primer nedavnih, kineskih, direktnih investicija. CRBC je takođe potpisao memorandum o razumevanju sa vladom Srbije o izgradnji auto-puta E763 koristeći model JPP. Pored toga, njene geo-ekonomske prednosti čine Srbiju povoljnim odredištem za strani kapital da odatle izvozi proizvode uglavnom na tržište EU. To znači da, posle godina prilagođavanja, kineske firme postepeno shvataju potencijal i mogućnosti srpskog tržišta.

\subsection{Institucionalna $i$ infrastrukturna povezanost}

Prilagođavanje lokalnim institucijama i normama je prvi i najvažniji zadatak za kineska preduzeća. U procesu projektovanja, budžetiranja, izgradnje, nabavke, podugovaranja i procene srpskog, Zemunskog mosta, kupovine

Xi Jinping, Enduring Friendship and True Partnership, June 16, 2016; http://www.chinadaily.com.cn/world/2016xivisitee/2016-06/16/content_25737654.htm; visited on December 10, 2019. 
Železare Smederevo i drugih projekata, kineske agencije su se striktno pridržavale lokalnih, pa čak i zakona i propisa EU i prihvatile nadzor lokalnog, nadzornog, inženjerskog tima i vlasnikovog tima za nadzor. To je dodatno podstaklo kinesku stranu da se prilagodi lokalnim pravilima i da bolje osmisli upravljanje projektima. Jačanje institucionalne povezanosti kineskih agencija i lokalnih tržišta je takođe glavna misija kineskih kompanija u susednim zemljama Srbije. Na primer, tender za hrvatski „Pelješki most” dobila je kompanija China Road and Bridge Corporate (CRBC, $\mathrm{u}$ daljem tekstu), pobedivši u javnom nadmetanju dva evropska konzorcijuma. Ovaj most je prvi veliki infrastrukturni projekat koji kineska preduzeća rea-lizuju na tržištu EU koristeći EU sredstva. CRBC se tokom postupka nadmetanja strogo pridržavala relevantnih zakona i propisa EU, oslanjajući se na izvrsne profesionalne veštine, niske troškove izgradnje, široko iskustvo upravljačkih kadrova i bogato međunarodno iskustvo za pobedu nad evropskim konkurentima.

S aspekta infrastrukturne povezanosti, deo projekata povezanih sa inicijativom PiP promovisao je međusobnu povezanost Srbije sa drugim zemljama Zapadnog Balkana i susedima iz EU. Postojeći putevi, mostovi i železničke pruge koje je Kina izgradila u srpskom i drugim delovima Zapadnog Balkana definitivno pomažu da se poboljša transportna mreža u regionu i pomognu zemljama regiona da se integrišu u panevropsku transportnu mrežu. Među njima, srpsko-mađarska železnička pruga je deo segmenta B Panevropskog koridora br. 10. Pelješki most povezuje dva dela Hrvatske, razdvojena Bosnom i Hercegovinom. Put E763 sa severnog produžetka crnogorskog auto-puta sever-jug deo je Panevropskog koridora. Vetroelektrane Mozula, zajednički projekat Šangajske elektroenergetske kompanije, Malteške energetske kompanije i vizije energetskog razvoja Crne Gore, koji ima važan praktični značaj za ulazak čiste i ekološki prihvatljive energije Crne Gore u EU pušten je u rad. Istovremeno, taj projekat je merilo saradnje Kine, Evrope i lokalne privrede.

\subsection{Društveni uticaj}

Već decenijama narodi Kine i Srbije neguju intenzivnu saradnju u oblastima obrazovanja, nauke i tehnologije, kulture i javnog zdravlja. Dve zemlje su se dogovorile da otvore kulturne centre, srpski u Kini i kineski u Srbiji. Kineski kulturni centar je završen u Beogradu, a Srpski kulturni centar je lociran u Pekingu. Instituti Konfučije postoje i pokrivaju oblasti kulture i obrazovanja na vodećim univerzitetima u Srbiji, Univerzitetu u Beogradu i u Novom Sadu, a kineski jezik postoji kao nastavni program na pilot osnovi 
u više od 100 osnovnih i srednjih škola u Srbiji. Sve ovo pokazuje društveni uticaj obeju zemalja jedne na drugu.

Izgradnja infrastrukturnih objekata u Srbiji koju obavljaju kineske kompanije važna je pokretačka sila koja Srbiju približava zemljama EU sa stanovišta ekonomskog razvoja. U isto vreme, kineske kompanije obučavaju i već su obučile određeni broj kvalitetnih, lokalnih, upravljačkih kadrova u građevinarstvu i talentovanih, građevinskih tehničara, popunjavajući na taj način praznine u oblasti lokalnog infrastrukturnog građevinarstva i obezbeđujući bazične, ljudske resurse koji omogućuju održivi razvoj ove privredne oblasti. Pored toga, kineske kompanije investiraju u izgradnju biciklističke staze u Beogradu, a donacija CBRC za završavanje reparacije mosta u dolini reke Tare u Crnoj Gori primer je aktivnog ispunjavanja društvene odgovornosti i jačanja povezanosti kineskih kompanija i lokalne zajednice.

U celini, infrastrukturna izgradnja u Srbiji u okvirima kineskih inicijativa 17+1 i Pojas i put imaju pozitivne efekte u procesu lokalnog, ekonomskog razvoja, poboljšanja infrastrukture i industrijskog razvoja i, takođe, pomažu procesu pridruživanja Srbije Evropskoj uniji. S druge strane, kineske kompanije mogu da koriste Srbiju i druge zemlje Zapadnog Balkana kao kapiju za ulaženje na tržište EU, prilagođavanje pravilima tog tržišta i sticanje iskustava na njemu.

\section{DA LI PRISUSTVO KINE OLAKŠAVA PRISTUPANJE SRBIJE EU? SUMNJE I ODGOVORI}

Zemlje Zapadnog Balkana, uključujući Srbiju, čine jugoistočnu granicu Evropske unije, pa je stabilnost ovog regiona ključna za bezbednost zemalja, članica EU. EU šalje poticajne signale zemljama Zapadnog Balkana da unaprede svoje reforme u političkom, ekonomskom i pravnom domenu i nudi pomoć Zapadnom Balkanu da dovrši institucionalnu transformaciju i postigne cilj evropske integracije. S obzirom na to da se SAD postepeno povlače sa Zapadnog Balkana, EU postaje najuticajniji akter i najveća zainteresovana strana u regionu. Iz perspektive ekonomske i trgovinske razmene, iako ukupan obim trgovine između EU i Zapadnog Balkana čini samo 1,3\% ukupnog obima trgovine EU, Zapadni Balkan je veoma važno potencijalno tržište. Sa bezbednosnog stanovišta, Zapadni Balkan je okružen zemljama EU i čini jugoistočnu barijeru EU. Stabilnost regiona je od presudne važnosti za sigurnost zemalja EU.

Međutim, posle pristupanja Hrvatske, tempo ekspanzije EU na istok je usporen. S jedne strane, EU mora da se suoči sa mnogim unutrašnjim pitanjima, kao što su evropska dužnička kriza, izbeglička kriza, Bregzit i porast 
desničarskog populizma; s druge, trenutni proces reformi i etnički odnosi na Zapadnom Balkanu nisu zadovoljavajući za EU. Zbog toga Unija, koja je orijentisana na norme, ne može mnogo da ulaže u ovaj region, što ometa proces pridruživanja Srbije i Crne Gore, a neke regije, kao što su Bosna i Hercegovina i Makedonija, čak doživljavaju stagnaciju u procesu pridruživanja. Kako su druge međunarodne snage sve aktivnije u regionu, EU je nedavno ponovo usmerila svoju pažnju na Zapadni Balkan s ciljem da potvrdi podršku EU perspektivama pridruživanja regiona dajući niz signala čiji je cilj da učvrste prisustvo EU u regionu. Na primer, u februaru 2018. Evropska komisija usvaja strateški dokument Novog Zapadnog Balkana, a slede samit EU - Zapadni Balkan u Sofiji, u maju, i Berlinski samit u Londonu, u julu, koji reafirmišu pozitivan stav EU prema primanju zemalja Zapadnog Balkana u svoje članstvo. Sve u svemu, četiri glavna aspekta politike EU prema Zapadnom Balkanu su normativni, finansijski, infrastrukturni i socijalni. Normativni aspekt podrazumeva da institucije, vrednosti i norme EU pozitivno utiču na zemlje Zapadnog Balkana koje su spremne da se pridržavaju institucija, vrednosti i normi EU, što odgovara Manersovoj ${ }^{5}$ tezi Normativna snaga Evrope (Normative Power Europe). Finansijski, EU obezbeđuje sredstva, na primer putem Instrumenta za pretpristupnu pomoć za regionalne zemlje, istovremeno uvodeći Okvir za ulaganja na Zapadnom Balkanu da bi podstakla više privatnih investicija u region. Infrastrukturno gledano, EU postepeno uključuje Zapadni Balkan u glavnu transevropsku transportnu mrežu, transevropsku energetsku mrežu i panevropske koridore, što tim zemljama omogućava bolji pristup povezivanju njihove transportne, telekomunikacione i energetske infrastrukture sa EU. Što se tiče građanskog društva, razmena ljudi između građana EU i Srbije održala se na pozitivnom nivou. Takođe, EU pruža pomoć balkanskim zemljama u pregovorima o regionalnom trgovinskom sporazumu i bilateralnom trgovinskom sporazumu sa EU.

Dok izgradnja u okviru inicijative PiP na Zapadnom Balkanu i dalje napreduje, zvaničnici i institucije EU postavljaju niz pitanja o aktivnostima kineskih kompanija u ovom „kvazi-EU” regionu. ${ }^{6}$ Shodno tome, reagovanje kineskih aktera na ova pitanja postalo je posebno važno za dalji razvoj PiP u ovom regionu. Ovaj deo rada tretira četiri glavne preokupacije EU i reagovanje kineske strane na njih u četiri odgovarajuće dimenzije.

Manners, Ian (2002), Normative Power Europe: A Contradiction in Terms?, JCMS: Journal of Common Market Studies, 40(2): 235-58.

$6 \quad$ South China Morning Post (2018), Merkel Warns Against China's Influence in Balkans, (22 Feb); Available at https://www.scmp.com/news/china/diplomacy-defence/ article/2134196/merkel-warns-against-chinas-influence-balkans, visited on December 10, 2019. 


\subsection{Politička budnost}

Pre svega, na normativnom i institucionalnom nivou, ideološke razlike se stavljaju u prvi plan. U izveštaju istraživanja MERICS smatra se da Kina osporava norme EU i promoviše kineski model. ${ }^{7}$ Nemački ministar spoljnih poslova Gabrijel kritikovao je Peking zbog toga što koristi PiP za stvaranje vrednosti drugačijih od zapadnog stila slobode i demokratije. ${ }^{8}$ Pored toga, EU izražava sumnju u tenderske metode za neke infrastrukturne projekte na Zapadnom Balkanu i ukazuje na moguću korupciju. ${ }^{9}$

U odgovoru na gorenavedena pitanja, normativno, očekivanje pridruživanja EU nateralo je Srbiju da kontinuirano reformiše svoj pravni, politički i ekonomski sistem u skladu sa EU standardima. Posle perioda „evropeizacije", relevantni standardi infrastrukturnih projekata u Srbiji u velikoj su meri usklađeni sa EU. Većina kineskih kompanija sarađivala je sa lokalnim pravnim firmama kako bi pratila stalno menjajući pravni sistem i strogo upravljala projektom, u skladu sa lokalnim zakonima i relevantnim EU regulativama. Istovremeno, nadzorni timovi u srpskim projektima često su sastavljeni uglavnom od zapadnoevropskih stručnjaka koji su vešti u primeni lokalnih i evropskih standarda. Pošteno je zaključiti da su norme i propisi EU poslužili kao merilo za ocenjivanje rezultata kineskih firmi u Srbiji. Pod ovom okolnošću, čak i ako kineski ugovornici dovode u pitanje standarde zemlje domaćina, oni uglavnom komuniciraju i razgovaraju sa vlasnicima na osnovu naučnih osnova, umesto da ih nameravaju zameniti kineskim standardima. Iako su neki projekti finansirani od Kine nailazili na otpor na Zapadnom Balkanu, glavni faktor nisu korupcija i drugi normativni sporovi.

\subsection{Ekonomska anksioznost}

Akteri iz EU zabrinuti su da će kineski fondovi koji ulaze na Zapadni Balkan, posebno u Srbiju, predstavljati prepreke na putu pridruživanja Srbije EU. Zbog hitne potrebe Srbije za finansijskom podrškom i mogućnosti EU da pruži pomoć u tom pogledu, spremnost Srbije da se pridruži EU odavno

$7 \quad$ Benner, Thorsten et al. (2018), Authoritarian Advance: Responding to China's Growing Political Influence in Europe", Global Public Policy Institute \& Mercator Institute for China Studies, Berlin, February 2018.

8 Hanschke, Hannibal, "Gabriel warnt Europäer vor Spaltungdurch China", Reuters, 30 August, 2017; Available at https://de.reuters.com/article/deutschland-eu-china-idDEKCN1BA1XU; visited on December 10, 2019.

9 Makocki, Michal and Zoran Nechev (2017), Balkan Corruption: the China Connection, European Union Institute for Security Studies (EUISS), Paris, July, 2017. 
je vrlo izražena, ali Srbija trenutno ne može da ispuni sve standarde EU jer proces reformi traje duže nego što se očekivalo, pa odlučnost EU o proširenju nije potpuno izvesna. Stoga EU ne može da uloži velike količine novca u region. Ulazak kineskog kapitala prekinuo je dug proces čekanja na pridruživanje i indirektno oslabio potrebu Srbije za sredstvima EU, što je zauzvrat oslabilo uticaj EU na regionalna pitanja. Takođe, MERICS izveštava da kineske investicije stižu uz političke uslove koji se svode na nameru Kine da poveća svoj uticaj u državama članicama EU i drugim zemljama u regionu kako bi se promenio odnos EU prema pitanjima kao što je slučaj Južnokineskog mora. ${ }^{10}$ Neke zemlje EU, posebno Nemačka, takođe imaju slične stavove.

Međutim, finansijska pitanja nesumnjivo postoje i već su podložna promenama. Zato što, u cilju pristupanja EU, treba da preskoči nekoliko ekonomskih pragova, Srbija je već odavno zabrinuta zbog svog prihvatanja prekomernih spoljnih zajmova, uključujući kredite iz Kine. To jasno pokazuje da uticaj EU u regionu nije značajno oslabljen učešćem kineskog kapitala. Istovremeno, u poređenju sa nekim fondovima EU (kao što su projekti Evropske banke za obnovu i razvoj), razlozi popularnosti kineskih koncesijskih zajmova u Srbiji su relativno niža kamatna stopa, duži rok otplate i veći iznos svakog, pojedinačnog zajma. Sa ove tačke gledišta, kineski fondovi su komplementarni EU fondovima, a ne zamena za njih. Štaviše, kineska strana počinje direktnije da ulaže u Srbiju i druge zemlje regiona, što znači da se način gradnje zasnovan na povlašćenim kreditima periodično zaustavlja. U budućnosti će sve veća kineska sredstva ući na lokalna tržišta u obliku direktnih investicija kroz saradnju sa evropskim i globalnim partnerima. ${ }^{11}$

\subsection{Zabrinutost za infrastrukturu}

Pored toga što ima određene sumnje u političke i ekonomske kineske aktivnosti u Srbiji, EU takođe izražava bojazan da kineski krediti Srbiji i drugim zemljama Zapadnog Balkana premašuju njihovu solventnost i uništavaju budući razvojni potencijal regiona, a sumnja se i na to da Kina postavlja 'dužničku klopku'. Na primer, EU je već poslala upozorenje o visokom nivou javnog duga Srbije. A projekat crnogorskog auto-puta sever-jug takođe

$10 \quad$ Benner, Thorsten et al. (2018), Authoritarian Advance: Responding to China's Growing Political Influence in Europe", Global Public Policy Institute \& Mercator Institute for China Studies, Berlin, February 2018.

11 Bastian, Jens (2017), The Potential for Growth Through Chinese Infrastructure Investments in Central and South-Eastern Europe Along the "Balkan Silk Road", Report prepared for the European Bank for Reconstruction and Development, Athens/London, July 2017. 
je $\mathrm{u}$ fokusu zapadnih kritičara. Projektu je u prvoj fazi potrebno ukupno 800.000 .000 evra, a 85\% finansiranja je preferencijalni kredit Kine, zbog čega javni dug Crne Gore čini više od $80 \%$ BDP-a. Čak i ako se plan za nadmetanje sprovodi u JPP režimu, neki posmatrači sumnjaju da bi mogući ekonomski obim Crne Gore i obim prihoda ostvarenih od saobraćaja na auto-putu sever-jug vrlo teško mogli da ostvare neki profit. ${ }^{12}$

Trenutno, infrastrukturni projekti kineskih agencija u celini su ili obnova postojećih projekata ili izgradnja novih koji zadovoljavaju hitne potrebe u Srbiji. Na primer, projekat auto-puta Srbije od Surčina do regiona Obrenovac deo je srpskog projekta puta E763, kao i deo koji ide kroz Panevropski koridor. Završavanjem projekta pomoći će se Srbiji da se bolje integriše u panevropsku transportnu mrežu. Kupovina Smederevske železare od strane kompanije Hebei Iron and Steel veliki je uspeh za obe zemlje jer ne samo da revitalizuje srpsku proizvodnju čelika i obezbeđuje brojne poslove za kvalifikovane radnike, već ima potencijal da ovu proizvodnju pretvori u ekološki prihvatljiv projekat na osnovu kineskog iskustva. U ovom smislu, projekat vetroelektrane, koji realizuje Shanghai Electric Power, je zelen, ekološki projekat koji koristi lokalnom okruženju i smanjuje cenu električne energije koja poboljšava životni standard lokalne populacije. To je jedan od pilot projekata inicijative PiP koji pokazuje da je visokokvalitetan razvoj osnovni cilj. Lokalni ljudi opšte prihvataju da infrastrukturni projekti koje vode kineske firme nisu samo u skladu sa zvaničnim planovima Panevropske transportne mreže i Panevropskog koridora, već su i komplementarni agendi interkonekcije Berlinskog procesa. Oni su u saglasju s agendom interkonekcije EU i podstiču duh prekogranične saradnje.

\subsection{Socijalni efekti}

Konačno, u EU se čuju glasovi da kineski infrastrukturni projekti mogu da imaju štetne efekte na društvo i životnu sredinu, koji će postati neodrživa. Neki naučnici ističu da Kina često precenjuje prelivanje pozitivnih efekata infrastrukturnih projekata i potcenjuje potencijalne rizike, bilo da su ekonomski, socijalni ili ekološki. ${ }^{13}$ Nasuprot tome, zapadne mere su više trans-akcione i uzimaju u obzir ekonomske, socijalne i ekološke posledice

12 Barkin, Noah (2018), Chinese 'Highway to Nowhere' Haunts Montenegro, Reuters (July 16th); Available at https://www.reuters.com/article/us-china-silkroad-europe-montenegro-insi/'chinese-highway-to-nowhere-haunts-montenegro-idUSKBN1K60QX; visited on December 10, 2019.

13 Bataineh, Bushra et al (2018), How the West Surrendered Global Infrastructure Development to China, Foreign Affairs (20 May); Available at https://www.foreignaffairs.com/ articles/china/2018-05-21/beijings-building-boom; visited on December 10, 2019. 
konkretnih projekata. Ove zaštitne mere su u interesu običnih ljudi u zemljama u razvoju.

Lokalni stanovnici su najbolje sudije socijalnim efektima kineskih projekata. Najveći broj anketiranih, bilo u institutima domaćinima, ili slučajno odabranih, izrazio je pozitivan utisak o kineskim aktivnostima u Srbiji. Kao što većina kineskih inženjera koji rade u Srbiji indicira, tokom procesa lokalnog delovanja, njihove kompanije uspevaju da predvide moguće društvene, ekonomske i ekološke opasnosti projekta i da preduzmu odgovarajuće mere da izbegnu ove probleme. Na primer, Kineska korporacija za puteve i mostove (China Road and Bridge Corporation) ne samo da striktno poštuje lokalne građevinske zahteve, već je obučila i grupu izuzetnih lokalnih talenata za dalji lokalni, industrijski razvoj. Pored toga, na primeru kupovine Smederevske železare, koju je kupila Hebei Steel Group, pokazuje da kineske kompanije shvataju društvenu odgovornost kao jedan od prioriteta svog lokalnog poslovanja.

Ukratko, susret Kine i EU na Zapadnom Balkanu, posebno u Srbiji, pokrenuo je niz spekulacija o njihovoj mogućoj konkurenciji ili saradnji u regionalnim poslovima. Analizom specifičnih praksi i dostignuća kineskih preduzeća u ostvarivanju projekata u okviru inicijative PiP u Srbiji, pouzdano se može zaključiti da trenutni napredak u izgradnji doprinosi sprovođenju EU strategije Zapadnog Balkana u celini i da podržava ekonomski razvoj Srbije. Na osnovi sopstvenih prednosti u pogledu kapitala i izgradnje, kineska strana doprinosi perspektivi Srbije da postane član EU. Iako se kineske kompanije takmiče sa evropskim lokalnim preduzećima kada otvoreno konkurišu za velike infrastrukturne projekte, to Kini i EU ne smanjuje prostor za bolju saradnju u regionu.

\section{ZAKLJUČCI}

U kontekstu pojačanog globalnog protekcionizma, stabilni odnosi Kine i EU su preduslov stalnom napredovanju inicijative PiP u Evropi. Kada se Kina i EU sastanu u Srbiji i drugim balkanskim zemljama, to da li će se uključiti u regionalnu konkurenciju ili produbiti saradnju na regionalnim poslovima imaće veliki uticaj na budući razvoj njihovih odnosa. Na osnovu analize strategije EU prema Srbiji i prema kineskim projektima u okviru inicijative PiP u ovoj zemlji, u pomenutom izveštaju se tvrdi da kineska ulaganja i infrastrukturni projekti koje finansira Kina imaju pozitivnu ulogu u poticanju Srbije da se pridruži EU. Kineska finansijska sredstva i tehnologije ne samo da promovišu kvalitetniji život ljudi u regionu, već pomažu u integraciji 
transportnih i energetskih mreža regiona u postojeće transevropske mreže i panevropske koridore. Pored toga, postoji dovoljno prostora za Kinu i EU da unaprede svoju saradnju u smislu postavljanja pravila, standarda, finansiranja i planiranja. U ovoj fazi, saradnja Kine i EU na Zapadnom Balkanu treba da se zasniva na „platformi za međusobnu povezanost Kina-Evropa” i da efikasno promoviše interkonekciju Kine i EU u smislu normi, standarda, finansiranja i planiranja.

Ukratko, u sadašnjoj fazi veliki broj infrastrukturnih projekata izgrađenih u okviru inicijative PiP u Srbiji pretvorio je planiranje panevropske transportne mreže u ovom regionu u stvarnost. Nije reč samo o povezanosti između PiP i strategije regionalnog proširenja EU, već se ovo može smatrati i početnom praksom u izgradnji platforme za međusobno povezivanje Kina-Evropa. Postojeća situacija ima potencijal da pomogne Kini i Evropi da iskoče iz načina razmišljanja po kome bi jedna strana sticala benefite na račun druge i da sarađuju na povezanosti Azije i Evrope.

Prevod

Zoran Pavlović

\section{LITERATURA}

1. Bastian, Jens, The Potential for Growth Through Chinese Infrastructure Investments in Central and South-Eastern Europe Along the 'Balkan Silk Road', Report prepared for the European Bank for Reconstruction and Development, Athens/ London, July 2017.

2. Barkin, Noah, "Chinese 'Highway to Nowhere' Haunts Montenegro", Reuters, July 16, 2018; Available at https://www.reuters.com/article/us-china-silkroad-europe-montenegro-insi/'chinese-highway-to-nowhere-haunts-montenegro-idUSKBN1K60QX, Dec 10, 2019.

3. Bataineh, Bushra et al., "How the West Surrendered Global Infrastructure Development to China", Foreign Affairs, (20 May); Available at https://www. foreignaffairs.com/articles/china/2018-05-21/beijings-building-boom, accessed on Dec 10, 2019.

4. Benner, Thorsten et al., "Authoritarian Advance: Responding to China's Growing Political Influence in Europe", Global Public Policy Institute \& Mercator Institute for China Studies, Berlin, February 2018.

5. "China, Serbia lift relations to comprehensive strategic partnership", Xinhua English, June 19, 2016; Available at http://english.sina.com/news/2016-0619/doc-ifxtfmrp2327200.shtml, accessed on Dec 10, 2019. 
6. Hanschke, Hannibal, "Gabriel warnt Europäer vor Spaltungdurch China", Reuters, 30 August, 2017; Available at https://de.reuters.com/article/deutschland-eu-china-idDEKCN1BA1XU, accessed on Dec 10, 2019.

7. Jinping, Xi, Enduring Friendship and True Partnership, June 16, 2016; Available at http://www.chinadaily.com.cn/world/2016xivisitee/2016-06/16/ content_25737654.htm, accessed on Dec 10, 2019.

8. Kolstø, Pål, "Western Balkans' as the New Balkans: Regional Names as Tools for Stigmatisation and Exclusion", Europe-Asia Studies, 68:7, 2016.

9. Makocki, Michal and Nechev, Zoran, "Balkan Corruption: the China Connection", European Union Institute for Security Studies (EUISS), Paris, July, 2017.

10. Manners, Ian, "Normative Power Europe: A Contradiction in Terms?", JCMS: Journal of Common Market Studies, 40(2), 2002.

11. Merkel Warns Against China's Influence in Balkans, South China Morning Post, Feb 22, 2018; Available at https://www.scmp.com/news/china/diplomacy-defence/article/2134196/merkel-warns-against-chinas-influence-balkans, accessed on Dec 10, 2019.

12. Todorova, Maria, Imaging the Balkans, Oxford: Oxford University Press, 1996. 